\title{
Inheritance and Protection of Intangible Cultural Heritage of the Yi People's Twelve-beast Dance
}

\author{
Lingzhi Xiao \\ Yunnan Agricultural University \\ Kunming, China 650201
}

\author{
Jun Wang* \\ Yunnan Agricultural University \\ Kunming, China 650201 \\ *Corresponding Author
}

\begin{abstract}
The ethnic and folk cultural heritage of Yunnan Province is relatively rich, especially the intangible cultural heritage related to sports. The intangible culture has undergone tremendous changes in the form of the social environment and national culture on which it depends, and some intangible cultural heritage is disappearing. At this stage, the people of our country pay more and more attention to the inheritance and protection of intangible cultural heritage, and it is necessary to strengthen the inheritance and protection of intangible cultural heritage. This paper is mainly aimed at the study of the Chuxiong Yi people's twelve-beast under the intangible cultural heritage of sports. Clarify the culture of the twelve-beast, improve the understanding of the beliefs and traditional culture of the $\mathrm{Yi}$ people in the twelve-beast, enrich the diversity of the traditional culture of the nation, and enhance the national cohesion. It is of great positive significance to make socialism sustainable development.
\end{abstract}

Keywords-Yi people; twelve-beast dance; sports intangible cultural heritage; inheritance; protection

\section{INTRODUCTION}

China's sports intangible cultural heritage has a history of thousands years of development and is an important part of intangible culture and modern sports culture. Especially in the folk dance, it can be said that it is the originator of the current dance. They have the most primitive dance movements and are the vane of modern dance innovation. The twelve-beast dance is a member of the intangible culture, so we have the responsibility to protect and pass on it, let it come from the same line and pass on from generation to generation. This article takes the twelve-beast dance as an example to analyze the protection of intangible cultural heritage and discusses its inheritance and protection.

\section{CHARACTERISTICS OF SPORTS INTANGIBLE Cultural Heritage}

China has a rich intangible cultural heritage of sports. Its sports projects are numerous and rich. It not only bears the characteristics of intangible cultural heritage, but also its own characteristics of sports. It is an indispensable part of sports.

*Fund Project: National Social Science Fund Project (18BTY068); Science Planning Project of Yunnan Province Research Interpretation and Study of Party's 19th National Congress Spirit (YB2017107).

\section{A. Characteristics of Intangible Culture}

Intangible culture is not a negative form of material form culture, but a culture that does not need to be expressed and passed down in material form. Intangible culture relies on people's oral and personal experience to express and pass on Sports intangible cultural heritage is carried out with sports, activities and human beings as carriers, and passed on through people's oral and sports experience. It is a historical symbol of people's participation in sports, a vane for competitive sports, and a living fossil for carrying forward national traditions. Therefore, in the protection and inheritance of intangible cultural heritage, the inheritance mode, origin, methods, sports culture and other aspects should be considered. In the protection of sports intangible cultural heritage, it is necessary to grasp the characteristics of the intangible culture of sports, and highlight the characteristics and rules of sports activities. Sports intangible culture is divided into dance, competition, folklore, acrobatics and other different types. They also have different meanings of background, and are protected and passed down by people, thus highlighting the national spirit and sports culture.

\section{B. Ethnic Regionality and Characteristics}

China is a country with vast land and abundant resources. It has a large population, up to 56 ethnic groups. Because of the different geographical environment, each ethic group has its own traditional culture and customs. The sports intangible culture is a sport activity that is spontaneously organized and created by the people. For example, there are Northern kicks and Southern fists in the martial arts, there are Wudang in the south and Shaolin in the north; For dance it also has a variety of ways, the peacock dance of the Dai people, the swing dance of the Tujia people, the bronze dance of the Miao people, the Mongolian dance, the Zhuang dance, Xinjiang dance and other ethnic dances. In terms of geographical environment, the representative sport in the South is the dragon boat race. Due to the abundant water resources in the south, the dragon boat race in the Dragon Boat Festival is very popular every year. The representative sport in the north is horseback archery. Due to the sparsely populated northern areas, with endless prairies, it is easy to ride a horse on the grassland, which is conducive to the development of this sport. 
Different ethnic groups have different humanistic feelings and customs, and sports intangible cultural heritage is no exception, it has its own national characteristics and features. At this stage, there are nearly 40 intangible cultural heritages in the UNESCO Intangible Cultural Heritage List, of which 14 are ethnic minorities. In the intangible cultural heritages, ethnic minorities play an important role.

\section{ANALYSIS ON THE ORIGIN OF THE TWELVE-BEAST DANCE OF CHUXIONG YI PEOPLE}

Located in the central part of the Yunnan-Guizhou Plateau, Chuxiong Yi Autonomous Prefecture is surrounded by mountains and rivers with beautiful scenery and a suitable climate. Chuxiong is a region where ethnic minorities gathered together. There are 29 ethnic groups including Han, $\mathrm{Yi}$ and Hui. The Yi people occupy the main population of ethnic minorities and have a strong national culture. The Chuxiong $\mathrm{Yi}$ people are naturally cheerful and straightforward, they worship nature and animals, they believe that everything is spiritual, especially tigers, so they attach great importance to the tiger sacrifice. The Yi people believe they are tiger clan, tiger is one of the Chinese zodiac signs, they consider tiger is their ancestor, the other eleven beasts led by the tiger are worshiped by the Yi people. The culture of the tiger has infiltrated all aspects of Yi people's life. For example: tiger head caps, tiger head bellyband, tiger head shoes in the Yi costumes, and the four-armed and eighttiger Taiji figure on the back cloth, the four tiger figure on the satchel, and the threaded tiger head combination on the pleated skirt, they are the legacy of the totem worship of the tiger; the Yi people will consider tiger days as the best day for be ancestor sacrifice, marriage, housewarming, and the opening of the shop. The twelve-beast dance of the Chuxiong Yi people are the sacrificial activities originated from folk traditions, which is very similar to the primitive human farming, animal husbandry and primitive reproduction.

\section{A. The Connection between Faith and the Twelve-beast Dance}

The reason why the twelve-beast dance can be circulated so far is because of the aesthetic consciousness and traditional beliefs of the Yi people. According to legend, a long time ago, the $\mathrm{Yi}$ people thought that they were the descendant of tigers, since they lived in deep mountains, the female tiger was not at home all the year round, and the male tiger was lack of security, therefore, the Yi people used to sacrifice female tigers in order to protect their homeland, which has become the faith and spiritual sustenance of the Yi people. The Yi people have experienced a long period of primitive living conditions, living in extremely harsh environments and difficult living situations. National cohesion is one of the important conditions for defeating the natural environment. They believe that the power of nature is caused by the evil in the hands of demons and ghosts. In order to overcome these so-called evil forces, they pray for the power of God to help. So they created the soul of the ancestors (totem) according to their own imagination and cognition, and believed that under the protection of the female tiger god, they will live peaceful and harmony. At the same time, they can be brave as a tiger to overcome difficulties. The Twelve Beast Dance expresses the fear and worship feelings of the tiger during the ritual process, and tells the descendant how to worship the ancestors and pray for the blessing of the gods to overcome the power of evil.

\section{B. The Manifestation of the Twelve-beast Dance}

The twelve-beast dance has a long history and full of rustic charm. It has a high degree of participation and appreciation, it can accurately reflect the social ideology of the Yi people at that time. The twelve-beast dance mainly headed with female tiger played by Yi women, followed are rabbit, dragon, snake, horse, sheep, monkey, chicken, dog, pig, rat, and cattle eleven female beasts. The female tiger will bring the other 11 female beasts back to the village, indicating that the village has a good weather, good harvest, and prosperity. This dance is mainly produced by the fusion of folk rituals and traditional music, and is one of the phenomena of national traditional culture. Its action form is mainly derived from the life of the Yi people, and arranged according to the movements of people's work, the dance movements are complicated, such as: farming, textile, harvesting and other action forms during farming and family work. The manifestation of the dance is mainly that the dancers paint the lines of the beasts in the exposed parts; the natural branches, canes, hides, leaves are used as the costumes to perform the mimicry of the twelve-beast. In addition to showing the actions of farming, the dance performances also include praise songs for the twelve-beast and the prayers of respecting the female tiger, which fully reflect the industrious and brave, unrestrained and simple national character of the Yi people, and it is also a symbol of national cohesion.

The formation of the twelve-beast dance is mainly circle dance, determinant group dance and pair dance. Circle dance is one of the most typical dance styles, it has a long history and is common among different ethnic groups, tribes and villages. The twelve-beast dance mainly centered on the gluten, the dancers make the rhythm sounds and dance counterclockwise, conveying the national respect for the faith and the cohesiveness of the nation; The determinant group dance is an activity of religious belief, the singing and dancing atmosphere is both serious and lively; Pair dance is a two-person dance or a multi-person dance. The dance style eliminates the people's solemnity to sacrifices, but promotes the emotion between people and fully reflects the harmonious scene of national harmony.

\section{The VAlue of the Yi PeOPle's TwelVE-BEAst DANCE}

\section{A. The Historical Value of the Twelve-beast Dance}

The twelve-beast dance was passed down from generation to generation by the Yi people. It can be seen from the costume matching, dance movements and lyric requirements of the dance that it witnessed the historical development of the Yi people and the respect of people for life, so it has important historical significance. The 
movements of the twelve-beast dance are primitive and simple, reflecting the simple and yet gorgeous dances of the Yi people and the primitive farming and animal husbandry. They are witnesses to the development history of the Yi society.

\section{B. The Cultural and Artistic Value of the Twelve-beast Dance}

The value of culture lies in satisfying people's various needs, and the cultural value itself is extremely diverse. The Twelve Beast Dance itself is an art dance that returns to the original ecology. It does not have a pretentious and exaggerated retouching action to please people. People can use their innate physical conditions and voices to express their own unique dance characteristics and unique singing voice, exudes Yi people's advocate of national spirit and national belief. The twelve-beast dance is rich in content, which not only expresses the original music, dance and poetry, but also combines national beliefs, national spirits, national languages, national art and national customs. As an original ecological dance, it is like a witness to history, showing people the lifestyle and customs of the original Yi people. This kind of dance has been passed down from generation to generation and has a strong vitality. It is a living cultural art of the Yi people.

\section{The Artistic Value of the Twelve-beast Dance}

As the original Yi people's twelve-beast dance, it has the essentials of the original dance dynamics. It focuses on the primitive and simple dance movements to express the Yi people's self-improvement, positive and optimistic attitude towards life, it is the main feature of the original dance of ethnic minorities and an indispensable part of the dance; the fusion of the twelve-beast dance and the sacrifice activities is an important part of the traditional national culture. The solemn and elegant sacrificial activities are manifested by the twelve-beast dance to show the sanctity of the national belief, the alternation of singing and dancing makes the sacrificial activities more colorful, and is an important expression of the sacrificial activities; since the twelve-beast dance has been passed down from generation to generation, it has a high artistic aesthetic value and reflect the habit of cultivating and living of the Yi people's ancestors in the dance, it interpreted the harmony with nature and harmonious coexistence, let the viewers have a feeling of returning to the truth and spiritual shock feeling, so it is a valuable asset of the Yi people's spirit and dance custom culture.

All in all, the twelve-beast dance of the Yi people is an indelible important part of folk dance and an intangible cultural heritage in history and culture. It reflects the true meaning of the Yi people's life and the love of life from the heart. The Yi people blend nature with the twelve-beast dance, leaving their beliefs and cultures deeply imprinted in the world. It originates from life and closely related to life.

\section{THE INHERITANCE AND PROTECTION OF THE YI PEOPLE'S TWELVE-BEAST DANCE}

With the continuous advancement and development of modern society, the social function of the Yi people's twelve-beast dance continues to expand, and its cultural value is increasingly valued by people, but the results of intangible cultural heritage should not be displayed on pictures and video materials, it should be presented and protected in the national inheritance and performance. Nowadays, under the market of information globalization, the national traditional culture has been greatly impacted, and such a tradition is on the verge of extinction. The traditional folk dance needs to be passed down and developed, it should exert its greatest value and let more people from society and the world to know it, to understand it, to promote the intangible cultural heritage with a positive attitude, make it to promote the economic development of tourism, to disseminate excellent national culture and to expand the lifestyle of the nation's strong health and fitness.

\section{A. The Inheritance Crisis Faced by the Twelve-beast Dance}

The inheritance and development of national traditional culture have limitations and obstacles such as national culture, regional geography, cultural changes, information globalization, and the times. The Chuxiong Yi people's twelve-beast dance belong to the folklore's most primitive ethnic folk traditional cultural activity which combine sacrificial offerings, singing and dancing, and entertainment, it is also the original worship activity that worship the female tiger gods. With the entry of modern culture and the impact of the world's culture, the twelve-beast dance originally in the Chuxiong Yi people were widely circulated among the people, but now they are rare and face the situation of cultural disappearance. This national folk culture entertainment performance which combines the twelve-beast dance and the sacrifice has a wide range of movements and a strong national culture connotation which is inherited by Bimo. Nowadays, it is only a few old Yi people who know the skills of the twelve-beast dance, the young dancers are influenced by the market and modern dance, most of them have abandoned the study of the twelve-beast dance, which has been greatly hindered in inheritance. With such a serious trend, the team that inherits the twelve-beast dance must be strengthened.

\section{B. The Idea of the Government and the People in Inheriance and Protection of the Twelve-beast Dance}

On the government side, first it is necessary to carry out and improve the construction of the national traditional cultural heritage team. Go deep into the folk culture of the Yi people and pay more attention to the Yi people's twelvebeast dance. After affirming the value of the twelve-beast dance, we will organize and resume the work of dance, sacrifice, and custom. The dance will be rehearsed to maintain the original characteristics of the twelve-beast dance, resume the performance and show it to the world. The Yi twelve-beast dance was announced by the Provincial People's Government in September 2009 as the second batch of provincial protection list. Secondly, the association of the 
twelve-beast dance will be established to organize and protect the folk dance talents of the twelve-beast dance. The folk artists who mastered the twelve-beast dance will be awarded the title of the artist of the twelve-beast dance, and they will conduct commendation so that the folk artists could come to them for study and observation. At last, strengthen the propaganda intensity of the twelve-beast dance, spread the folk dance in the means of communication such as the Internet media and the news media, and raise people's awareness of protection and the "mission" of inheriting the intangible cultural heritage.

In terms of the public, the twelve-beast dance can be first carried out as a tourism development project. On one hand, there are economic effects in tourism, which can solve the dancers' daily living expenses and salary problems. On the other hand, it can let the tourists experience the culture of the twelve-beast dance in person, so that the tourists can still remember the memories and learn the connotation of the Yi culture and fell the national customs from them. Secondly, the $\mathrm{Yi}$ twelve-beast dance will enter the classroom, strengthen students' understanding of the traditional folk culture and art, and enrich the students' after-school knowledge, which will help students to develop their interest and learn the dance. In the dance competition, the folk dance will be added, and the dancers are intentionally added to the classroom of the twelve-beast dance to learn and communicate. Finally, twelve-beast dance can be carried out as a fitness program. People who exercise regularly can improve their own functions, improve their habits of living and working, and improve immunity and delay aging. The twelve-beast dance is suitable for both men and women, it is based on entertainment, during the process it not only carries forward the national cultural characteristics, but also inherits the traditional folk culture. It can be said to kill two birds with one stone.

\section{CONCLUSION}

In the process of continuous development and progress of human society, intangible cultural heritage has undergone the baptism of the times and the challenges of countless cultures. It has gone through the vicissitudes of the years, but it still exists, so it must have the meaning of its existence in the world. The Yi twelve-beast dance is an important part of the folk dance of ethnic minorities, it keep standing in the flow of the years. Dance is like everything in the world, it has its own laws of development. The sports intangible cultural heritage is closely related to everyone, it is not just to preserve some kind of lost folk dances, but to discover the valuable sports culture through its research and record and then passed down it. The twelve-beast dance is a form of action, using body language to express the reverence of the $\mathrm{Yi}$ people and their love for life, it is an important manifestation of external language and inner emotion. Sports intangible cultural heritage has a strong communication function, it not only meets people's daily needs, but also enhances national sentiments, it is an indispensable part of world culture. The record of sports intangible cultural heritage may be more important than protection, sometimes the power of action cannot be quantified, but it can fully discover the value of the twelve-beast dance to the world and show people the great and magical power of the twelve-beast dance.

\section{REFERENCES}

[1] Ba Hongmei. A Brief Discussion on the Expressions and Cultura Functions of the Chuxiong Yi people's twelve-beast Dance[J].Journal of Yunnan Arts University,2013(04):86-88.

[2] Pu Lichun, Shen Jing. Investigation on the current situation of the Protection and Inheritance of Intangible Cultural Heritage of Yunnan Minority Groups[J]. Journal of Minzu University of China (Philosophy and Social Sciences),2012,39(05):64-68.

[3] Zhao Kening, Yu Zhenkai. Protection and Inheritance of Hani Traditional Sports Culture from the Perspective of Intangible Culture[J]. National Art Research, 2010, 23(06): 101-105.

[4] Zhu Weiming, Sun Xiying, Yi Zhicheng, Lin Shanghu. Research on the Development of National Traditional Sports in the Perspective of Intangible Culture[J]. Journal of Physical Education Institute of Shanxi Normal University, 2010, 25(01): 70-72.

[5] $\mathrm{Hu}$ Minzhong. On Material Culture and Intangible Culture [J]. New Vision, 2008 (01): 73-75.

[6] Liu Mingge. On the Inheritance, Protection and Utilization of Intangible Cultural Heritage in Folk Customs[J]. Jianghan Forum, 2012(10): 119-125 